\title{
The Importance of the Therapeutic Care Plan in Colorectal Surgery
}

\author{
Henrique Carvalho e Silva Figueiredo ${ }^{10}$ Isaac José Felippe Corrêa Neto ${ }^{2(}$ Jéssica Mocerino ${ }^{10}$ \\ Mariana Campello de Oliveira ${ }^{1}$ () Laercio Robles $^{30}$
}

1 Physician and former student of Santa Marcelina College, Department of General Surgery and Coloproctology Service, Hospital Santa Marcelina, São Paulo, SP, Brazil

2 Physician specialist in Coloproctology and professor at Santa Marcelina College, Department of General Surgery and Coloproctology Service, Hospital Santa Marcelina, São Paulo, SP, Brazil

3 Physician specialist in Coloproctology, professor at Santa Marcelina College and head of the Department of General Surgery,

Department of General Surgery and Coloproctology Service, Hospital Santa Marcelina, São Paulo, SP, Brazil
Address for correspondence Isaac José Felippe Corrêa Neto, Professor of Faculdade Santa Marcelina, Hospital Santa Marcelina, São Paulo-SP, Brazil (e-mail: isaacneto@hotmail.com).

J Coloproctol 2021;41(4):425-429.

\begin{abstract}
Keywords

- therapeutic plan

- risk management

- colorectal surgery

Introduction A therapeutic plan is elaborated based on the health needs of each user, allowing a multidisciplinary team to assess diagnoses, treatment options, bonds, and optimal hospitalization time.

Objectives To identify risk management tools already used and implemented in a reference teaching hospital in the city of São Paulo and to analyze their application and risk factors in medium and large colorectal surgery.

Method Observational, longitudinal, and prospective study, with 30 patients with colorectal disease hospitalized in the surgical ward of the coloproctology service and in need of surgical treatment. In the first group, the protocol was applied with the knowledge of the researcher only, and, in the second group, with the knowledge of both the researcher and the attending physicians.

Results Sixty percent of the patients were female with a mean age of 60.93 years and body mass index (BMI) of $26.07 \mathrm{Kg} / \mathrm{m}^{2}$.

After surgery, patients in the first group who did not receive venous thromboembolism (VTE) prophylaxis in the first 24 hours had an increased risk of having the event compared with those who returned to prophylaxis $(p<0.005)$, thus suggesting this prophylaxis was a protective factor against thromboembolic event $(p=0.006)$. This group also had a higher risk of hypoglycemia when no strict control was performed $(p=0.041)$.

Conclusion The compliance to hospital protocols with application monitoring, notedly in teaching places with annual admission of resident physicians, is a fundamental part of the adequate care of the patient combined with the implementation of therapeutic plans.
\end{abstract}

received

January 16, 2021

accepted after revision

August 6, 2021
DOI https://doi.org/

10.1055/s-0041-1740097. ISSN 2237-9363. (c) 2021. Sociedade Brasileira de Coloproctologia. All rights reserved.

This is an open access article published by Thieme under the terms of the Creative Commons Attribution-NonDerivative-NonCommercial-License, permitting copying and reproduction so long as the original work is given appropriate credit. Contents may not be used for commercial purposes, or adapted, remixed, transformed or built upon. (https://creativecommons.org/ licenses/by-nc-nd/4.0/)

Thieme Revinter Publicações Ltda., Rua do Matoso 170, Rio de Janeiro, RJ, CEP 20270-135, Brazil 


\section{Introduction}

Medium and high complexity health care-at the levels of specialties, and diagnostic and propaedeutic support-traditionally uses therapy and focuses mainly on the disease, concentrating less on the subject of its treatment, and with little involvement of the family, history, culture, daily life, and quality of life. ${ }^{1}$

Thus, the use of hard technologies (machines and instruments) prevails in the mode of health production, to the detriment of light-hard (defined by technical knowledge) and light (relationship technologies) technologies for patient care. $^{2}$

Changing the care model requires an appreciation of light technologies in the line of care to be used in health production. A work process centered on light and light-hard technologies is the condition for the service to provide a better and more appropriate care for patients and their families. $^{3,4}$

In the meantime, with greater use of technical knowledge and better doctor-patient relationship, the therapeutic plan is elaborated based on the health needs of each user, considering their opinions, wants, and life project, which allows for a more democratic and horizontal interaction between doctor, patient, and family through a welcoming and bonding relationship of co-responsibility and autonomy, encouraging the adoption and understanding of the proposed treatment.

The health care of patients hospitalized for surgical procedures involves the work of a multidisciplinary team in order to assess diagnoses, treatments, bonds, and treatment time. $^{5-9}$ In addition, it assists in decision-making and favors the sharing of information with the patient, allowing the adoption of conducts together through an individualized therapeutic plan, providing a common understanding of the proposal, management, roles, and responsibilities of each individual. ${ }^{10-16}$

However, the application of predictive models for patient risk stratification and surgical practice in the form of efficient and reproducible decision support systems seems to be still limited. Incorporating decision support tools based on robust predictive modeling into broader systematic approaches to patient evaluation allows to increase patient safety. ${ }^{17,18}$

\section{Objectives}

The present study aimed to identify risk management tools already used and implanted in a reference teaching hospital in the city of São Paulo and to analyze their application and risk factors in large colorectal surgery.

\section{Methodology}

This is an observational, longitudinal, and prospective study, with 30 patients with colorectal disease in need of large surgical treatment treated in the coloproctology outpatient clinic and admitted to the surgical ward of the hospital Santa Marcelina for this specialty.
Patients hospitalized with colorectal diseases without surgical indication, those in hospital beds other than the specialty ward, and those who did not agree to participate in the study were excluded.

Based on anamnesis and instruments for risk management disseminated in the hospital environment, due to their respective theoretical and scientific importance in patient management, a protocol and better adhering to those already existing in the institution were structured. For their analysis, the patients were divided into 2 groups, each containing 15 individuals.

In group 1, composed of the first 15 patients, the protocol was applied, with new parameters and measures already managed, with the researcher's knowledge only, so that the resident and assistant physicians did not know that the stipulated parameters were being evaluated. In group 2, composed of the 15 subsequent patients, the same items were analyzed, but this time, with the standardization of the therapeutic plan and knowledge of the researcher and the multidisciplinary team.

The data evaluated in the two groups were:

\section{Preoperative}

- general data on anamnesis: gender, age, body mass index (BMI)

- reason for hospitalization: neoplastic disease or not

- smoking and/or alcohol consumption

- chronic medications: drug reconciliation

- venous thromboembolism (VTE) risk

- anesthetic risk classification: American Society of Anesthesiologists (ASA)

\section{Postoperative}

- VTE risk and prophylaxis

- risk and measures for hypoglycemia

- doubts after the surgical procedure

- return in consultation with pathological anatomy result

- return in consultation with nutritionist with scheduled date

All patients who agreed to participate in the study were offered a free and informed consent form (TCLE, in the Portuguese acronym) after the acceptance of the research ethics council (CEP, in the Portuguese acronym) under number 2,622,762.

\section{Statistical analysis}

The statistical study was initially done from the descriptive analysis of the variables, followed by the univariate based on Student t-tests for independent samples and on the chi-squared test for categorical data, which was considered statistically significant if $p<0.05$ with a confidence interval $>95 \%$.

Finally, the relative risk of the variables that maintained independent associations in the factors studied and in relation to complications was calculated. The calculations were performed using the IBM SPSS Statistics for Windows, Version 20.0 (IBM Corp., Armonk, NY, USA). 


\section{Results}

Thirty patients with colorectal disease requiring major surgical treatment for intestinal resection followed at the coloproctology outpatient clinic between October 2017 and May 2018 were prospectively analyzed, and the first 15 patients were designated as group 1, in which only the researcher was aware of the methodology; the other 15 patients were designated as group 2, in which the researcher and the medical and multidisciplinary teams were aware of the proposal of the work.

Group 1 consisted of $60 \%$ of female patients with a mean age of 62.2 years ( \pm 8.24 years) and mean BMI value of 25.94 $\mathrm{Kg} / \mathrm{m}^{2}\left( \pm 5.20 \mathrm{Kg} / \mathrm{m}^{2}\right), 60 \%$ of the patients in this group were Caucasian, followed by Brown (33.3\%), and Black (6.7\%). On the other hand, group 2 was also composed by $60 \%$ of female patients, however with a mean age of 57 years ( \pm 16.74 years) and mean BMI value of $26.20 \mathrm{Kg} / \mathrm{m}^{2}\left( \pm 4.96 \mathrm{Kg} / \mathrm{m}^{2}\right)$, with $60 \%$ being Caucasian, followed by Brown (20\%), Blacks (13.3\%), and Asian (6.7\%) (-Table 1).

It was found that, in group $1,80 \%$ of the causes of hospitalization was due to neoplastic disease, while in group 2 , it was $93.3 \%$. Regarding habits, such as smoking and alcohol consumption, it was found, respectively, that $73.3 \%$ and $60 \%$ had these addictions in group 1 against $46.7 \%$ and $53.3 \%$ in group 2 (- Table $\mathbf{1}$ ).

In Group 1,60\% of the patients used chronic medication and $6 \%$ of them did not have drug reconciliation performed at admission, and, in the postoperative period, in $26.6 \%$ of the patients, chronic drugs were not reintroduced at the correct time. In counter-departure, in group $2,66.7 \%$ of the patients used chronic medication and, with the best supervision, all

Table 1 Characteristics of patients in groups

\begin{tabular}{|l|l|l|}
\hline Parameter & Group 1 & Group 2 \\
\hline Number of patients & $15(50 \%)$ & $15(50 \%)$ \\
\hline Age in years (mean \pm SD) & $62.2 \pm 8.24$ & $57 \pm 16.74$ \\
\hline Sex & & \\
\hline Male & $6(40 \%)$ & $6(40 \%)$ \\
\hline Female & $9(60 \%)$ & $9(60 \%)$ \\
\hline Ethnicity & & \\
\hline Caucasian & $9(60 \%)$ & $9(60 \%)$ \\
\hline Brown & $5(33.3 \%)$ & $3(20 \%)$ \\
\hline Black & $1(6.7 \%)$ & $2(13.3 \%)$ \\
\hline Asian & & $1(6.7 \%)$ \\
\hline BMI (mean \pm SD) & $25.94 \pm 5.2$ & $26 \pm 4.96$ \\
\hline Reason for hospitalization & & \\
\hline Malignant disease & $12(80 \%)$ & $14(93.3 \%)$ \\
\hline Benign disease & $3(20 \%)$ & $1(6.7 \%)$ \\
\hline Smoking positive & $11(73.3 \%)$ & $7(46.7 \%)$ \\
\hline Positive ethylism & $9(60 \%)$ & $8(53.3 \%)$ \\
\hline
\end{tabular}

Abbreviations: BMI, body mass index; SD, standard deviation.
Table 2 Univariate analysis

\begin{tabular}{|l|l|l|}
\hline Parameter & $p$ & Exposure risk $(95 \% \mathrm{CI})$ \\
\hline $\begin{array}{l}\text { VTE risk without } \\
\text { prophylaxis }\end{array}$ & 0.005 & $1.738(1.357-1.826)$ \\
\hline $\begin{array}{l}\text { Protective factor of } \\
\text { VTE with prophylaxis }\end{array}$ & 0.006 & $0.476(0.353-0.541)$ \\
\hline Alcoholism & 0.006 & $1.938(1.938-4.522$ \\
\hline Smoking & 0.062 & $1.231(1.083-6.358)$ \\
\hline ASA & 0.043 & $1.450(1.136-1.851)$ \\
\hline $\begin{array}{l}\text { Time glucose in } \\
\text { non-DM }\end{array}$ & 0.041 & $0.365(0.017-0.747)$ \\
\hline Time glucose in DM & 0.011 & $0.267(0.269-0.440)$ \\
\hline
\end{tabular}

Abbreviations: ASA, American Society of Anesthesiologists; $\mathrm{Cl}$, confidence interval; DM, diabetes mellitus; VTE, venous thromboembolism.

had their medications introduced in hospitalization and in the immediate postoperative period.

Regarding postoperative complications, it was shown that it was higher in alcoholic patients $(p=0.006)$ and smokers $(p=0.062)$ and in those classified as anesthetic risk ASA 3 $(p=0.043)$ (-Table 2). When multivariate analysis of the data presented in this table, it was observed that the main independent factor for postoperative complications was alcohol consumption $(p=0.06)$.

Regarding the prevention and VTE risk, patients in both groups received adequate preoperative prophylaxis; however, no patient in the first group had Wells risk stratification. ${ }^{19}$ From these, $20 \%$ were at risk for pulmonary thromboembolism (PTE), 6.7\% of whom were at high risk and 93.3\% were at moderate risked; in addition, it was observed that $13.3 \%$ did not return to prophylaxis after surgery. In relation to group 2 , there was a risk for PTE in $6.7 \%$ of the patients, all of them at moderate risk, and of these, all of them had both their risk stratification by Wells criteria and prophylaxis and return in the immediate postoperative period.

It was observed that patients who did not return to VTE prophylaxis had a theoretical risk 1.73 higher of having thromboembolic events than those who returned to drug prophylaxis in the postoperative period (odds ratio [OR] $=1.73, p=0.005$ ) (-Table 2 ). In addition, it was demonstrated that the reintroduction of prophylaxis of thromboembolic events was a possible protective factor against the occurrence of VTE with statistical significance $(p=0.006$ and $\mathrm{OR}=0.47$ [0.353-0.541]) (-Table 2).

Regarding the possibility of hypoglycemia, there was a risk of $86.6 \%$ in group 1 and 100\% in group 2, although only $60 \%$ in the first group received routine prophylactic support against $100 \%$ in the protocol action group. Also in this respect, the strict postoperative time glucose was not performed in $73.3 \%$ of the patients in group 1 , and it was observed that the patients in whom the strict control of blood glucose was performed in the postoperative period had lower chances of hypoglycemia, even if no adverse event was demonstrated in the others $(p=0.041)$ (-Table 2). 
Among the 15 patients in group 1, 20\% reported having doubts about the treatment, and, at the first outpatient consultation after hospital discharge, $13.3 \%$ of them left with some type of inquiry against none in group 2 $(p=0.355) ; 66.7 \%$ of patients did not take the result of pathological anatomy in the consultation; besides that, the same percentage had no consultation with a scheduled nutritionist. On the other hand, in group 2, all patients brought the pathological result to the follow-up consultation with the assistant team, although $13.3 \%$ did not have a consultation scheduled with the nutrition group.

\section{Discussion}

Adequate multidisciplinary preparation of hospital records is an inherent premise in health care. On the medical side, the existence of a medical record committee is mandatory in all hospitals, and, fundamentally, in university institutions, the standardization and detailed preparation of medical records is important, since care, teaching, and research activities are practiced. ${ }^{20}$ However, Silva and Tavares Neto demonstrated through the analysis of medical records of 77 institutions that, in $48.1 \%$ of the cases, not even the therapeutic plan was specified in anamnesis. ${ }^{20}$

Associated with the detailed completion of the various items of the medical records, the adoption of a therapeutic plan in health care allows better programming and the occurrence of lower rates of failure and damage in patient care, besides greater participation of the family and multidisciplinary integration.$^{1,21}$

In this context of therapeutic plan, the present study demonstrates that although it is already known that VTE corresponds to the main cause of avoidable death in hospitalized patients $\mathrm{s}^{22}$ and that the performance of abdominalpelvic and oncological surgeries are important risk factors for the treatment of this condition, ${ }^{23}$ in group 1 , no patient was stratified based on objective parameters or scales of risk assessment for VTE, although 19\% of patients received drug prophylaxis at the time of hospitalization.

After surgery, $13 \%$ of patients in group 1 did not return to prophylaxis in the first 24 hours, thus increasing by 1.73 times (1.357-1.826) the potential risk of having VTE when compared with those who returned to prophylaxis $(p=0.005)$ and a possible significant protection factor when performing the postoperative return of prevention verified in patients in group 2 ( $p=0.006$ and $\mathrm{OR}=0.47[0.353-0.541]$ ).

The present study also corroborates data from the literature, in which, according to the ENDORSE study that analyzed 30,000 surgical patients in 32 countries, only $64 \%$ of these patients at risk of VTE received prophylaxis. ${ }^{24}$ In Brazil, this number is more importantly reduced, as $46 \%$ of VTE prophylaxis was performed correctly in patients admitted to reference hospitals. ${ }^{25}$

Among other items that should be contained in the therapeutic plan, there is a need to know comorbidities, medications in use, performance and programming of fundamental postoperative care and multidisciplinary care for surgical patients. In this respect, it is known that adequate and rigorous glycemic control during the perioperative period demonstrates an increase in survival and decrease in postoperative complications in both diabetic and non-diabetic patients. ${ }^{26}$

In the present study, it was found that only $30 \%$ of the first sample of patients had strict capillary glycemia in the first 24 hours postoperatively, and, of these, $86.6 \%$ had some risk for hypoglycemia, demonstrating data consistent with the literature, in which blood glucose monitoring occurred in only $59 \%$ of hospitalized patients, and only $54 \%$ of patients with altered examination received treatment for control. ${ }^{27}$ On the other hand, in relation to group 2, in which the supervision of this measure was intensified and standardized, it was observed that these patients had lower chances of hypoglycemia $(p=0.041)$.

Although, in this study, no statistically significant data were found between smoking habits and postoperative complications ( $p=0.062)$ - perhaps due to the small number of patients studied-the literature demonstrates a $30 \%$ increase in the potential risk of morbidity and mortality within 30 days of the surgical procedure and the risk of infection. ${ }^{28,29}$ In addition, in the alcoholic patients, this risk was 1.9 times higher with statistical significance $(p=0.006)$.

The elaboration and implementation of a therapeutic plan involves individual and collective action. For this, it is essential to organize individualized multidisciplinary care to the patient, based on the evaluation of the clinical case in an expanded way, therapeutic objectives, intervention proposals, and evaluation of results.

This action of the health team aims to minimize failures in health work processes and possibility of damage, to better program bed turnover, as well as more effective communication between teams, providing important metrics for programs such as Enhanced recovery after surgery (ERAS) in various surgical specialties.$^{30-32}$

As limiting factors of the present study, we can mention the small number of patients analyzed and in a non-randomized manner, and only one surgical service having been used. On the other hand, its application was made by a single observer, longitudinally and prospectively.

\section{Conclusion}

In the present study, it was observed that the compliance to hospital protocols with application monitoring, notedly in teaching places with annual admission of resident physicians, is a fundamental part of the adequate care of the patient, and, combined with the implementation of therapeutic plans, it was shown to decrease the risk of occurrence of VTE and hypoglycemia.

Conflict of Interests

The authors have no conflict of interests to declare.

\section{References}

1 Mattos RA. A integralidade na prática (ou sobre a prática da integralidade). Cad Saude Publica 2004;20(05):1411-1416

2 Campos GWS. Subjetividade e administração de pessoal: considerações sobre modos de gerenciar o trabalho em equipes de 
saúde. In: Merhy EE, Onocko R. organizadores. Agir em saúde: um desafio para o público. São Paulo: Editora Hucitec; 1997:229-266

3 Franco TB, Magalhães HM Jr. In O Trabalho em Saúde: olhando e experienciando o SUS no cotidiano; HUCITEC, 2004-2a. edição; São Paulo, SP.

4 Pinto DM, Jorge MSB, Pinto AGA, et al. Projeto terapêutico singular na produção do cuidado integral: uma construção eletiva. Texto Contexto Enferm 2011;20(03):493-302

5 Pinheiro R, Mattos RA. Cuidado: as fronteiras da integralidade. Rio de Janeiro: Hucitec/Abrasco; 2004:57-74

6 McNair AGK, Choh CTP, Metcalfe C, et al. Maximising recruitment into randomised controlled trials: the role of multidisciplinary cancer teams. Eur J Cancer 2008;44(17):2623-2626

7 Twelves CJ, Thomson CS, Young J, Gould AScottish Breast Cancer Focus Group and Scottish Cancer Therapy Network. Entry into clinical trials in breast cancer: the importance of specialist teams. Eur J Cancer 1998;34(07):1004-1007

8 Kelly SL, Jackson JE, Hickey BE, Szallasi FG, Bond CA. Multidisciplinary clinic care improves adherence to best practice in head and neck cancer. Am J Otolaryngol 2013;34(01):57-60

9 Gabel M, Hilton NE, Nathanson SD. Multidisciplinary breast cancer clinics. Do they work? Cancer 1997;79(12):2380-2384

10 Stacey D, Bennett CL, Barry MJ, et al. Decision aids for people facing health treatment or screening decisions. Cochrane Database Syst Rev 2011;(10):CD001431

11 Volandes AE, Paasche-Orlow MK, Barry MJ, et al. Video decision support tool for advance care planning in dementia: randomised controlled trial. BMJ 2009;338(01):b2159. Doi: 10.1136/bmj. b2159

12 Steel N. Thresholds for taking antihypertensive drugs in different professional and lay groups: questionnaire survey. BMJ 2000;320 (7247):1446-1447

13 Joosten EA, DeFuentes-Merillas L, de Weert GH, Sensky T, van der Staak CP, de Jong CA. Systematic review of the effects of shared decision-making on patient satisfaction, treatment adherence and health status. Psychother Psychosom 2008;77(04):219-226

14 Strong S, Paramasivan S, Mills N, Wilson C, Donovan JL, Blazeby JM. 'The trial is owned by the team, not by an individual': a qualitative study exploring the role of teamwork in recruitment to randomised controlled trials in surgical oncology. Trials 2016; 17(01):212-220

15 Helmreich RL, Schaefer HG. Team performance in the operating room. In M. S. Bogner (Ed.), Human error in medicine. Lawrence Erlbaum Associates, Inc.; 2014:225-253

16 Mazzocco K, Petitti DB, Fong KT, et al. Surgical team behaviors and patient outcomes. Am J Surg 2009;197(05):678-685

17 Burtscher MJ, Manser T. Team mental models and their potential to improve teamwork and safety: A review and implications for future research in healthcare. Saf Sci 2012;50(05):1344-1354
18 Buchlak QD, Yanamadala V, Leveque JC, Sethi R. Complication avoidance with pre-operative screening: insights from the Seattle spine team. Curr Rev Musculoskelet Med 2016;9(03):316-326

19 Wells PS, Anderson DR, Bormanis J, et al. Value of assessment of pretest probability of deep-vein thrombosis in clinical management. Lancet 1997;350(9094):1795-1798

20 Silva FG, Tavares-Neto J. Avaliação dos Prontuários Médicos de Hospitais de Ensino do Brasil. Rev Bras Educ Med 2007;31(02): 113-121

21 Hamilton DW, Heaven B, Thomson RG, Wilson JA, Exley C. Multidisciplinary team decision-making in cancer and the absent patient: a qualitative study. BMJ Open 2016;6(07):e012559

22 Tooher R, Middleton P, Pham C, et al. A systematic review of strategies to improve prophylaxis for venous thromboembolism in hospitals. Ann Surg 2005;241(03):397-415

23 Leite SMO, Maia CLS Jr, Silveira AM. Tromboembolismo venoso e câncer colorretal: um desafio para o cirurgião. Relato de caso e revisão de literatura. Rev Bras Coloproctol 2011;31(02):200-204

24 Barros-Sena MA, Genestra M. Profilaxia da trombose venosa profunda em pós-operatórios de cirurgias ortopédicas em um hospital do Rio de Janeiro Brasil. Prática Hospitalar; 2008:150-156

25 Cohen AT, Tapson VF, Bergmann JF, et al; ENDORSE Investigators. Venous thromboembolism risk and prophylaxis in the acute hospital care setting (ENDORSE study): a multinational crosssectional study. Lancet 2008;371(9610):387-394

26 Rogers SO Jr, Zinner MJ. The role of perioperative hyperglycemia in postoperative infections. Adv Surg 2009;43(01):103-109

27 Kwon S, Thompson R, Dellinger P, Yanez D, Farrohki E, Flum D. Importance of perioperative glycemic control in general surgery: a report from the Surgical Care and Outcomes Assessment Program. Ann Surg 2013;257(01):8-14

28 Sharma A, Deeb AP, Iannuzzi JC, Rickles AS, Monson JR, Fleming FJ. Tobacco smoking and postoperative outcomes after colorectal surgery. Ann Surg 2013;258(02):296-300

29 Richards CH, Platt JJ, Anderson JH, McKee RF, Horgan PG, McMillan DC. The impact of perioperative risk, tumor pathology and surgical complications on disease recurrence following potentially curative resection of colorectal cancer. Ann Surg 2011;254(01):83-89

30 Simpson JC, Bao X, Agarwala A. Pain Management in Enhanced Recovery after Surgery (ERAS) Protocols. Clin Colon Rectal Surg 2019;32(02):121-128

31 Ji HB, Zhu WT, Wei Q, Wang XX, Wang HB, Chen QP. Impact of enhanced recovery after surgery programs on pancreatic surgery: A meta-analysis. World J Gastroenterol 2018;24(15):1666-1678

32 Forsmo HM, Pfeffer F, Rasdal A, Sintonen H, Körner H, Erichsen C. Pre- and postoperative stoma education and guidance within an enhanced recovery after surgery (ERAS) programme reduces length of hospital stay in colorectal surgery. Int J Surg 2016;36 (Pt A):121-126 